\title{
Forming of Communicative and Communication Competence in Future Specialists of Vocational Education in Virtual Learning Environment of Computer Science Discipline
}

\author{
Yashanov Serhii \\ Doctor of Pedagogical Sciences, Full Professor \\ Dragomanov National Pedagogical University (Ukraine, Kyiv) \\ Bidenko Eugene \\ Senior lecturer \\ Dragomanov National Pedagogical University (Ukraine, Kyiv) \\ Nazarenko Viktor \\ Postgraduate \\ Dragomanov National Pedagogical University (Ukraine, Kyiv)
}

\begin{abstract}
The article characterizes modern approaches to teaching information disciplines in a virtual environment of teaching establishment. The concept of virtual learning environment is defined. The interpretation of communicative and communication competence is presented. The main directions of indirect pedagogical communication in the virtual learning environment of computer science disciplines are described. The communicative requirements to the organization of training of computer science disciplines on the basis of the virtual learning environment are analyzed and defined. The structure of communicative and communication competence is described. Identified the tools by which indirect learning is implemented in a virtual learning environment. A partial teaching methodology is proposed, which is implemented in a virtual learning environment. The structure of electronic educational and methodical complexes are characterized, which includes autonomous, local and distance educational courses and methodical support for their use in a specific computer science discipline placed in a virtual learning environment. The components of electronic educational and methodical complexes that reflect the author's concept of formation of communicative competencies and provide the implementation of the methodical system of teaching computer science disciplines in the virtual learning environment are analyzed. The method of teaching computer science disciplines in a virtual environment is described.

Key words: virtual learning environment, computer science disciplines, formation of communicative and communication competence, future specialists of professional education, electronic educational and methodical complexes.
\end{abstract}

Актуальність дослідження. Актуальність питання розвитку методики навчання дисциплін інформатичного циклу, обумовлена процесом інформатизації освіти, яка передбачає інтеграції віртуального середовища навчання (BCH) на основі інформаційних і комунікаційних технологій (IКТ) з традиційним навчальним процесом. Відповідно у педагогічних технологіях та методиках навчання інформатичних 
дисциплін, відбувається істотна зміна характеру педагогічної взаємодії: процес навчання реалізується у віртуальному навчальному середовищі (BНC) закладу вищої педагогічної освіти (ЗВПО). Зважаючи на те, що становлення і розвиток у майбутніх фахівців професійної освіти комунікаційної компетентності, характеризує рівень освоєння інформаційно-комунікаційних технологій, системна інформатизація вищої педагогічної освіти суттєво відбивається у змісті, методах, засобах і формах навчання, а ефективність використання комунікаційних технологій у навчальному процесі безпосередньо залежить від рівня комунікаційної компетентності фахівців професійної освіти та викладачів дисциплін інформатичного циклу, які здійснюють комунікацію у віртуальному середовищі навчання.

У цьому сенсі потребують детального дослідження компоненти комунікаційної компетентності (цільова, мотиваційна, змістовна i процесуальна складові) i комунікативних компетентностей (базова i спеціальна складові), що розширює понятійний апарат теорії і методики навчання інформатичних дисциплін у ВСН та теоретичні основи побудови та застосування електронних навчально-методичних комплексів (ЕНМК) з інформатичних дисциплін, як основи віртуального середовища навчання.

Метою статті $є$ дослідження сучасних підходів, теоретичних та методичних засад формування комунікативної та комунікаційної компетентності майбутніх фахівців професійної освіти під час навчання інформатичних дисциплін у віртуальному освітньому середовищі.

Виклад основного матеріалу. У сучасній педагогічній та методичній літературі поняття віртуального середовища навчання визначається як сукупність взаємопов'язаних компонентів - суб'єктів навчального процесу та інформаційноосвітнього середовища, що включає електронні освітні ресурси і засоби комунікації на основі IKT [4].

На сьогодні у педагогічній науці розроблені різні компоненти теоретичних передумов використання можливостей засобів IKT у $\mathrm{BCH}$ при формуванні комунікативних компетентностей студентів ЗВПО: психологічний i технологічний підходи до комп'ютерно-опосередкованої педагогічної комунікації, взаємодії в інформаційно-освітньому середовищі (Т.Н. Носкова [4], I.M. Розіна [6]); 
компетентнісний підхід до побудови та дослідження освітніх процесів (О.М. Спірін [7], Н.В. Морзе [3]); особливості організації навчального процесу з використанням ІКТ (М.I. Жалдак [1], С.М. Яшанов [8; 9]),

Комунікативні і комунікаційні компетентності (виділені нами при аналізі робіт Т. Н. Носкової [4] і I. М. Розіної [6] для характеристики гуманітарної та програмнотехнічної складових педагогічної взаємодії), що формуються при вивченні дисциплін інформатичного циклу, носять загальнонавчальний характер.

Аналіз робіт присвячених різним ектам комп'ютерно-опосередкованої педагогічної комунікації у віртуальному середовищі навчання інформатичних дисциплін [1-9], показує, що цей процес розглядається як система, що об'єднує очну і дистанційну форми організації навчального процесу засобами ВСН і передбачає використання безпосередньої міжособистісної комунікації суб'єктів навчального процесу і навчальну взаємодію, опосередковану віртуальним середовищем навчання ЗВПО (рівні «один до одного», «один до багатьох», «багато до багатьох»).

Комунікативні вимоги до організації навчання інформатичних дисциплін на основі ВСН передбачають: миттєвий зворотний зв'язок, блочно-модульну структуру навчального контенту та включення до складу необхідних методичних засобів, наявність засобів контролю і самоконтролю та демонстраційних прикладів 3 лабораторних, самостійних і контрольних робіт [1].

Комп'ютерно-опосередкована педагогічна комунікація під час навчання інформатичних дисциплін майбутніх фахівців професійної освіти на основі ВСН повинна мати визначені комуніканти, методичний інтерфейс і бази комунікантів. Під комунікантами розуміються суб'єкти навчального процесу, що використовують засоби комунікаційних технологій для взаємодії з інформаційним ресурсом [2].

Методичний інтерфейс реалізується засобами комунікації в програмній системі навчання на основі ВСН, що включає в себе засоби управління контентом і управління навчанням [4], а бази комунікантів розглядаються як компоненти комунікативної та комунікаційної компетентностей.

Комунікативна компетентність передбачає наявність комплексу знань, умінь і досвіду ефективної діяльності зі здійснення інформаційної взаємодії (передача і сприйняття сенсу) між комунікантами [3]. 
У структурі комунікативної компетентності зазвичай виокремлюється базова та спеціальна компоненти.

Базова компонента характеризує реалізацію у процесі навчання інформатичних дисциплін комп'ютерно-опосередкованої комунікації у межах ВСН, що здійснюється за допомогою освітніх ресурсів, спроектованих на базі інструментальних програмних засобів загального призначення. Відображає системність і повноту знань, наявності умінь із використання комунікантами засобів IКТ для вирішення навчальних завдань, досвіду їх практичної реалізації.

Спеціальна компонента характеризує реалізацію у межах ВСН комп'ютерноопосередкованої комунікації, що здійснюється за допомогою дистанційних курсів, розроблених і супроводжуваних у програмній системі навчання на основі засобів ІКТ. Відображає системність і повноту знань і умінь із використання комунікантами засобів систем управління навчанням і управління контентом у ВСН для вирішення навчальних завдань, наявність досвіду їх практичної реалізації.

Комунікаиійна компетентність розглядається нами як комплекс знань, умінь та досвіду ефективної діяльності з використання комунікаційних технологій у навчальній та професійній діяльності.

Структура комунікаційної компетентності передбачає наявність трьох складових [7].

Цілемотиваційна компонента характеризує установку на освоєння прийомів роботи із засобами ВСН, мотивацію навчально-професійної діяльності студентів майбутніх фахівців професійної освіти.

Змістовна компонента відображає системність і повноту знань про засоби комунікаційних технологій, про взаємодію комунікантів у віртуальному середовищі навчання інформатичних дисциплін.

Прочесуальна компонента характеризує рівень освоєності прийомів роботи із засобами ВСН, застосування теоретичних знань у практичній діяльності.

Інструментальні засоби ВСН включають локальні ресурси, які містять навчально-методичні матеріали, призначені для самостійного вивчення студентами (окремі веб-сторінки, книги, пояснення, статичні електронні навчально-методичні комплекси) та інтерактивні ресурси, що реалізують опосередковане навчання у ВСН на 
основі комп'ютерно орієнтованих засобів і здійснюють комунікацію між суб'єктам процесу навчання інформатичних дисциплін (включають завдання, тести, глосарії, динамічні електронні навчально-методичні комплекси).

Основним дидактичним завданням при навчанні інформатичних дисциплін у ВСН є розвиток комунікаційної компетентності студентів, яка обумовлює формування їх комунікативних компетентностей [4; 6]. В межах загальної методики навчання на основі комп'ютерно орієнтованих засобів, заснованої на нелінійних освітніх технологіях, можна запропонувати часткову методику навчання, що реалізується у ВСН за наступними напрямками:

1. Цільове призначення методики навчання інформатичних дисциплін у ВСН: 1) розвиток комунікаційної компетентності студентів; 2) освоєння студентами засобів комунікаційних технологій; 3) здобування знань, формування умінь і досвіду діяльності з використання засобів IКТ у ВСН.

2. Зміст методики навчання інформатичних дисциилін у ВСН: 1) інваріантна частина включає в себе модулі, призначені для організації різних форм навчальної діяльності (аудиторні заняття, самостійна робота і контроль знань) на основі ІКТ у ВСН; 2) варіативна частина містить модулі методичного супроводу дисциплін інформатичного циклу на базі інструментальних програмних засобів загального призначення і програмних систем навчання у ВCH.

3. Застосування методики навчання інформатичних дисциплін у ВСН: 1) наочні, практичні і проектні методи навчання забезпечуються використанням системи управління навчанням 3 організацією комп'ютерно-опосередкованої педагогічної комунікації та різних форм навчальної діяльності, включенням в структуру кожного навчального модуля авторських методичних розробок; 2) використовуються форми організації процесу навчання інформатичних дисциплін на основі комп'ютерно орієнтованих засобів, які передбачають поєднання очної та дистанційної форм навчання і забезпечують у ВСН персоналізацію навчання; 3) основним засобом навчання у ВСН $\epsilon$ електронний навчально-методичний комплекс (ЕНМК).

ЕНМК 3 дисциплін інформатичного циклу включають в себе автономний освітній курс, локальний освітній курс, дистанційний курс та методичне забезпечення щодо використання дистанційного курсу конкретної дисципліни розміщеної у ВСН та 
інструкція викладачеві з розробки дистанційних курсів в системі Moodle.

Компоненти ЕНМК відображають авторську концепцію формування комунікативних компетентностей i забезпечують реалізацію методичної системи навчання інформатичних дисциплін у ВСН. Зазвичай це стосується етапів проектування ЕНМК і критеріїв ефективності його компонентів; видів супроводу компонентів ЕНМК у віртуальному середовищі навчання інформатичних дисциплін, що враховують рівні опосередкованої взаємодії суб'єктів навчального процесу з освітнім ресурсом і критерії якості навчання.

Отже, методика навчання інформатичних дисциплін у ВСН включає в себе поетапне освоєння трьох основних груп дій: 1) розробку електронних освітніх ресурсів на базі інструментальних програмних засобів загального призначення в межах виконання проектних завдань передбачених у ВСН; 2) взаємодію у ВСН з освітнім ресурсом конкретної дисцииліни за допомогою локального освітнього курсу, розробленого i супроводжуваного на базі інструментальних програмних засобів загального призначення; 3) взаємодію у ВСН 3 освітнім ресурсом конкретної дисципліни за допомогою дистанційного курсу, розробленого і супроводжуваного в програмній системі на основі комп’ютерно орієнтованих засобів ВСН.

Такий підхід до використання засобів ВСН забезпечує: 1) методичний супровід у процесі навчання інформатичних дисциплін інструментальних i комунікаційних комп'ютерно орієнтованих засобів навчання, методичного забезпечення лабораторних i самостійних робіт з дисциплін інформатичного циклу; 2) зміну комунікативних ролей суб'єктів процесу навчання інформатичних дисциплін у ВСН (ролі викладача наставництво, роль студента - організатор власної цілеспрямованої самостійної роботи); 3) підвищення рівня сформованості комунікаційної компетентності при вивченні дисциплін інформатичного циклу на базі різноманітного інструментарію ВСН за рахунок варіативної частини навчального контенту; 4) системне формування комунікативних компетентностей, обумовлене розвитком комунікаційної компетентності при вивченні дисциплін у ВСН на базі ЕНМК; 5) реалізацію різних технологій взаємодії суб'єктів процесу навчання інформатичних дисциплін з освітнім ресурсом ВСН і видів педагогічної комунікації за рахунок розробки та супроводу компонентів комплексу на базі інструментальних програмних засобів загального 
призначення і програмної системи навчання; 6) підвищення кількісних характеристик педагогічної комунікації (час комунікації, рівень домінування, кількість видів і рівнів комп'ютерно-опосередкованої педагогічної взаємодії) за рахунок методичного супроводу та інтеграції навчальних модулів освітніх програм з інструментальними i комунікаційними можливостями ВСН.

Насамкінець потрібно зауважити, що методика навчання інформатичних дисциплін майбутніх фахівців професійної освіти у віртуальному середовищі навчання буде ефективною, якщо при організації навчання будуть дотримані наступні умови: 1) реалізація у $\mathrm{BCH}$ інформатичних дисциплін комп'ютерно-опосередкованої комунікації при розробці і експлуатації електронного освітнього ресурсу повинна відбуватися на рівнях «один до одного», «один до багатьох» і «багато до багатьох»; 2) системне здійснення модульного структурування та інтерактивності освітнього ресурсу; 3) реалізація у ВСН інформатичних дисциплін наочних, практичних і проектних методів, індивідуальних і групових форм навчання; 4) системне використання ВСН інформатичних дисциплін для організації ефективної взаємодії між викладачем і студентом.

Висновки. Наприкінці зазначимо, що нами було здійснено дослідження теоретичних і методичних засад формування комунікативної та комунікаційної компетентності майбутніх фахівців професійної освіти під час навчання інформатичних дисциплін у віртуальному освітньому середовищі, яке дало змогу констатувати, що системне використання педагогічно виважених інструментальних засобів (локальних і інтерактивних ресурсів) у віртуальному середовищі навчання інформатичних дисциплін, забезпечує ефективне здійснення педагогічної комунікації, а отже і системне формування комунікативної та комунікаційної компетентності на основі доцільної реалізації визначених принципів навчання, наочних, практичних і проектних методів навчання, індивідуальних і групових форм навчання у віртуальному освітньому середовищі закладів вищої педагогічної освіти.

\section{References}

1. Zhaldak M. I. Ispolzovanie sredstv sovremennykh informaczionnokommunikaczionnykh tekhnologij $v$ uchebnom proczesse dolzhno byt pedagogicheski vyverennym [The use of modern information and communication technologies in the educational process should be pedagogically verified] // Informatizacziya obrazovaniya: 
teoriya i praktika: mezhdunar. nauchno-praktich.konf.: sb. materialov; pod obshhej redakcziej M.P. Lapchika. Omsk : Poligraficheskij czentr KAN, 2015. P. 24-28.

2. Intelektualnyi rozvytok doroslykh u virtualnomu osvitnomu prostori [Intellectual development of the grown-ups in the virtual light space]: monohrafiia / [Smulson M. ta in.]. Kyiv : Pedahohichna dumka, 2015. $221 \mathrm{p}$.

3. Morze N. V., Hlazunova O.H. Formuvannia ta otsiniuvannia IKkompetentnostei naukovo-pedahohichnykh pratsivnykiv $v$ umovakh vprovadzhennia dystantsiinykh tekhnolohii [Forming and evaluation of informatics competence of scientific and pedagogical staff in conditions of distance learning technologies introduction]. Informatsiini tekhnolohii $i$ zasoby navchannia. 2012, No. 6 (32). URL: http://journal.iitta.gov.ua/ index.php/itlt/article/view/758

4. Noskova T. N. Pedagogicheskaya sushchnost' virtual'noj obrazovatel'noj sredy [The pedagogical essence of the virtual educational environment. Izvestiya RGPU im. A.I Gercena. 2014. No. 167. P. 183-194.

5. Petko L. V. Informatsiyno-navchalne seredovische yak umova formuvannya profesiyno orientovanogo inshomovnogo navchalnogo seredovischa $v$ umovah universitetu [Information and teaching environment as a condition of professionally oriented foreign language teaching environments formation in the terms of the university] // Informatsiyni tehnologiyi u profesiyniy diyalnosti: Tr. IX Vseukr. nauk.-prakt. konf., Ryvnenskiy derzh. gumanytarniy un-t, 25 bereznya 2015 m. Ryvne, 2015. P 89-91.

6. Rozina I. N. Pedagogicheskaya komp'yuterno-oposredovannaya kommunikaciya: teoriya i praktika [Pedagogical computer-mediated communication: theory and practice]. Moskva : Logos, 2005. 460 p.

7. Spirin O. M. Informatsiino-komunikatsiini ta informatychni kompetentnosti yak komponenty systemy profesiino-spetsializovanykh kompetentnostei vchytelia informatyky [Information and communication and informatic competences as komponents of the system of professional-specialized competences of informatics teacher] Informatsiini tekhnolohii $i$ zasoby navchannia. 2009. No. 5 (13). URL: http://www.ime.edu-ua.net/em.html

8. Yashanov S. M. Kompiuterne navchannia yak produkt lohichnoho rozvytku innovatsiinykh protsesiv $v$ osviti [Computer learning as a product of logical development of innovative processes in education]. Naukovi zapysky: zb. nauk. st. Kyiv : NPU. 2001. P. 191-198.

9. Yashanov S. M. Kontseptualni zasady proektuvannia systemy informatychnoi pidhotovky maibutnikh uchyteliv $v$ umovakh kompetentnisnoho pidkhodu [Conceptual bases of designing of system of computer training of future teachers in the conditions of the competence approach.]. Mizhnarodnyi naukovyi forum: Sotsiolohiia, psykholohiia, pedahohika, menedzhment : zb. nauk. pr. Kyiv: Tov «Nvp interservis», 2015. Vyp. 17. P. 181-190.

10. Yashanov S. Intehratsiia navchalnykh internet-resursiv u protses pidhotovky vchytelia do maibutnoi profesiinoi diialnosti [Integration of educational Internet resources in the process of preparing teachers for future professional activities]. Vyshcha shkola № 5/6. 2010. P. 47-54.

11. Holinska T., Komarovska O., Melnyk O., Pet'ko L., Shpitsa R., Sova O., Strohal T. Cloud Technologies in Art Entrepreneurship Education. Journal of Entrepreneurship Education (JEI). USA. 2019. Vol: 22 Issue: 5. P. 1-6. 


\title{
Translation of the Title, Abstract and References to the Author's Language
}

\author{
УДК 378.018.43:004:[37.015.311:[005.336.2+316.77]] \\ Яшанов С., Біденко С., Назаренко В. Формування комунікативної та \\ комунікаційної компетентності майбутніх фахівців професійної освіти у \\ віртуальному середовищі навчання інформатичних дисциплін.
}

Анотація. Охарактеризовано сучасні підходи до навчання інформатичних дисциплін у віртуальному середовищі навчання вищого педагогічного закладу освіти. Визначено поняття віртуального середовища навчання. Представлено трактування комунікативної та комунікаційної компетентності. Охарактеризовано основні напрямки опосередкованої педагогічної комунікації у віртуальному середовищі навчання інформатичних дисциплін. Проаналізовано та визначено комунікативні вимоги до організації навчання інформатичних дисциплін на основі віртуального середовища навчання. Описано структуру комунікативної та комунікаційної компетентності. Визначено інструментальні засоби, за допомогою яких реалізується опосередковане навчання у віртуальному середовищі навчання. Запропоновано часткову методику навчання, що реалізується у віртуальному середовищі навчання. Охарактеризовано структуру електронних навчально-методичних комплексів, яка включає в себе автономний, локальний і дистанційний освітні курси та методичне забезпечення щодо їх використання 3 конкретної інформатичної дисципліни розміщеної у віртуальному середовищі навчання. Проаналізовано компоненти електронних навчально-методичних комплексів, що відображають авторську концепцію формування комунікативних компетентностей і забезпечують реалізацію методичної системи навчання інформатичних дисциплін у віртуальному середовищі навчання. Описано методику навчання інформатичних дисциплін у віртуальному середовищі.

Ключові слова: віртуальне середовище навчання, інформатичні дисципліни, формування комунікативної та комунікаційної компетентності, майбутні фахівці професійної освіти, електронні навчально-методичні комплекси.

\section{Література}

1. Жалдак М.И. Использование средств современных информационнокоммуникационных технологий в учебном процессе должно быть педагогически выверенным // Информатизация образования: теория и практика: междунар. научнопракт. конф. / Сборник материалов ; под общ. ред. М. П. Лапчика. Омск : Полиграфический центр КАН, 2015. С. 24-28.

2. Інтелектуальний розвиток дорослих у віртуальному освітньому просторі : монографія [Смульсон М. та ін.]. Київ : Педагогічна думка, 2015. 221 с.

3. Морзе Н. В., Глазунова О. Г. Формування та оцінювання ІК-компетентностей науково-педагогічних працівників в умовах впровадження дистанційних технологій. Інформаційні технологї $i$ засоби навчання. 2012. № 6(32). URL : http://journal.iitta.gov.ua/ index.php/itlt/article/view/758.

4. Носкова Т. Н. Педагогическая сущность виртуальной образовательной среды. Известия РГПУ им. А.И Гериена. 2014. № 167. С. 183-194.

5. Петько Л.В. Інформаційно-навчальне середовище як умова формування професійно орієнтованого іншомовного навчального середовища в умовах університету // Інформаційні технології у професійній діяльності: Тр. IX Всеукраїнської наук.-практ. 
конф., Рівненський державний гуманітарний ун-т, 25 березня 2015 р. Рівне, 2015. С. 8991.

6. Розина И. Н. Педагогическая компьютерно-опосредованная коммуникация: теория и практика. Москва : Логос, 2005. 460 с.

7. Спірін О. М. Інформаційно-комунікаційні та інформатичні компетентності як компоненти системи професійно-спеціалізованих компетентностей вчителя інформатики. Інформащійні технологї $i$ засоби навчання. 2009. № 5(13). URL : http://www.ime.edu-ua.net/em.html

8. Яшанов C. M. Комп’ютерне навчання як продукт логічного розвитку інноваційних процесів в освіті. Наукові записки: зб. наук. ст. Київ : НПУ, 2001. С. 191198.

9. Яшанов С. М. Концептуальні засади проектування системи інформатичної підготовки майбутніх учителів в умовах компетентнісного підходу. Міжнародний науковий форум: соиіологія, психологія, педагогіка, менеджмент : зб. наук. пр. Київ : ТОВ «НВП Інтерсервіс», 2015. Вип. 17. С. 181-190.

10. Яшанов С. Інтеграція навчальних інтернет-ресурсів у процес підготовки вчителя до майбутньої професійної діяльності. Вища школа № 5/6. 2010. С. 47-54.

11. Holinska T., Komarovska O., Melnyk O., Pet'ko L., Shpitsa R., Sova O., Strohal T. Cloud Technologies in Art Entrepreneurship Education. Journal of Entrepreneurship Education (JEI). USA. 2019. Vol: 22 Issue: 5. P. 1-6. 